\section{The Pharmacokinetics, Optimal Dose and Therapeutic Monitoring of Vancomycin in Severe Burn Patients}

\author{
Chien-Chih $\mathbf{W}^{1,3}$, Li-Feng $\mathrm{H}^{4}$, Jann-Tay $\mathbf{W}^{5}$, Shu-Wen $\mathrm{L}^{1,3}$ and Eng-Kean $\mathrm{Y}^{6 *}$ \\ ${ }^{1}$ Department of Pharmacy, National Taiwan University Hospital, College of Medicine, National Taiwan University, 7 Chung Shan S. Rd., Taipei, Taiwan \\ ${ }^{2}$ Graduate Institute of Clinical Pharmacy, College of Medicine, National Taiwan University, 33 Linsen South Road, Taipei, Taiwan \\ ${ }^{3}$ School of Pharmacy, College of Medicine, National Taiwan University, 33 Linsen South Road, Taipei, Taiwan \\ ${ }^{4}$ Center for Drug Evaluation, 3F No.465, Sec.6, Zhongxiao E. Rd, Taipei, Taiwan \\ ${ }^{5}$ Division of Infectious Diseases, Department of Internal Medicine, National Taiwan University Hospital, Taipei, Taiwan \\ ${ }^{6}$ Division of Plastic Surgery, Department of Surgery, National Taiwan University Hospital Yun-Lin Branch, Taipei, Taiwan
}

\begin{abstract}
Objectives: This paper investigated the pharmacokinetic (PK) change, optimal dose and therapeutic monitoring method of vancomycin in severe burns.

Method: This is a retrospective, matched cohort study. Nine burn patients were included, and each individual was matched with a control critically ill patient. Vancomycin concentrations were analyzed using the first order pharmacokinetic principles to calculate elimination rate constant $(K)$, half-life $\left(t_{1 / 2}\right)$, volume distribution $\left(V_{d}\right)$, total body clearance $\left(\mathrm{CL}_{\text {vancomycin }}\right)$ and the 24-hour area under the curve $\left(\mathrm{AUC}_{24 \mathrm{~h}}\right)$. Population PK analysis and Monte Carlo simulation was used to investigate optimal dose.

Results: The mean burn area of the burn group and age was $60 \%$ and 20 years-old respectively. The loading dose and daily maintenance dose was significantly higher in burn group than that in control group. Vancomycin clearance was significantly higher $(p<0.05)$ in burns patients when compared to control patients. $\mathrm{CL}_{\mathrm{Cr}}$ (creatinine clearance) was not significantly correlated to $\mathrm{CL}_{\text {vancomycin }}$ (vancomycin clearance) in both groups. $C_{\text {trough }}$ (serum trough concentration) was significantly correlated with $A \cup C_{24 h}$ in the control group $\left(r=0.98, R^{2=} 0.96, p<0.01\right)$, but not in the burn group $\left(r=0.63, R^{2}=0.40, P=0.07\right.$ ). Daily dose of $5000 \mathrm{mg}$ of vancomycin could achieve $90 \%$ probability of target attainment if target was $\mathrm{AUC}_{24 \mathrm{~h}} / \mathrm{MIC}$ (minimum inhibitory concentration) $>400$.

Conclusion: Two steady state concentrations but not $C_{\text {trough }}$ is an appropriate reference for vancomycin therapeutic monitoring. A daily dose of at least $5000 \mathrm{mg}$ is suggested in severe burn patients with normal renal function $\left(\mathrm{CL}_{\mathrm{Cr}}>90 \mathrm{~mL} / \mathrm{min}\right)$.
\end{abstract}

Keywords: Burns; Vancomycin; Pharmacokinetics; Optimal dose, Therapeutic drug monitoring

\section{Introduction}

Vancomycin, a potential nephrotoxic antibiotic, is commonly used in the treatment of methicillin-resistant Staphylococcus aureus (MRSA) infection or sepsis. The antibiotic is excreted by kidney and $55 \%$ of it is bound to albumin [1]. However, the pharmacokinetics (PK) is significantly altered in severe burn patients $[2,3]$. Previous studies have shown that the renal clearance and volume distribution $\left(\mathrm{V}_{\mathrm{d}}\right)$ of vancomycin in burns patients is higher than it is in controls, while the half-life is shorter [4-6]. Thus, larger loading and the use of more frequent dosing of vancomycin especially when intermittent dosing is used are needed to maintain therapeutic serum level, and inadequate dosing is not an uncommon clinical problem [7].

To monitor clinical efficacy, the $24 \mathrm{~h}$ area under the serum concentration-time curve to minimum inhibitory concentration ratio $\left(\mathrm{AUC}_{24 \mathrm{~h}}\right.$ : $\left.\mathrm{MIC}\right)$ of $>400$ has been suggested as a standard clinical reference for vancomycin dosing [8]. As $\mathrm{C}_{\text {trough }}$ significantly correlates with the $\mathrm{AUC}_{24} \mathrm{~h}$, a $\mathrm{C}_{\text {trough }}$ level of $15-20 \mathrm{mg} / \mathrm{L}$ is recommended to achieve an $\mathrm{AUC}_{24 \mathrm{~h}} / \mathrm{MIC}$ of 400 if the MIC is $1 \mathrm{mg} / \mathrm{L}$. However, its use as reference for dosage adjustment in severe burns patients has been questioned as the correlation of $\mathrm{C}_{\text {trough }}$ with $\mathrm{AUC}_{24 \mathrm{~h}}$ remains debatable in this special group $[9,10]$.

The main purpose of this retrospective study was to investigate the correlation of $\mathrm{C}_{\text {trough }}$ with $\mathrm{AUC}_{24 \mathrm{~h}}$ in severe burn patients. The burn patients in similar ages and injury mechanism from the 2015 Taiwan cornstarch dust explosion have provided a clinical model with least spatial and temporal effect. Another aim of this study was to define the optimal dose for this population to achieve $\mathrm{AUC}_{24 \mathrm{~h}} / \mathrm{MIC}>400$. The study obtained approval from The NTUH Ethics Committee (NTUH201508031DINA).

\section{Methods}

This is a retrospective chart review study. Thirty-three adult burn patients ( $>18$ years old) admitted to the National Taiwan University Burn centre following the color cornstarch powder explosion in a water park on June 28, 2015 were reviewed. Only those who received vancomycin therapy at least for 2 days after burn injury with peak $\left(\mathrm{C}_{\text {peak }}\right)$ and trough $\left(\mathrm{C}_{\text {trough }}\right)$ serum concentrations available were included in the study.

Patient demographic data including age, sex, height, weight, total

*Corresponding author: Dr. Eng Kean Yeong, Division of Plastic Surgery Department of Surgery, National Taiwan University Hospital Yun-Lin Branch, No. 579, Sec. 2, Yunlin Rd, Douliou City, Yunlin County 640,Taiwan, Tel: +886-927767676, Fax: +886-927-767676; E-mail: smartpace88@hotmail.com

Received September 30, 2018; Accepted October 20, 2018; Published October 24, 2018

Citation: Chien-Chih W, Li-Feng H, Jann-Tay W, Shu-Wen L, Eng-Kean Y (2018) The Pharmacokinetics, Optimal Dose and Therapeutic Monitoring of Vancomycin in Severe Burn Patients. J Mol Genet Med 12: 372 doi:10.4172/1747-0862.1000372

Copyright: $\odot 2018$ Chien-Chih W, et al. This is an open-access article distributed under the terms of the Creative Commons Attribution License, which permits unrestricted use, distribution, and reproduction in any medium, provided the original author and source are credited 
body surface area of burn (\%), timing of vancomycin infusion (day after burn injury), $\mathrm{S}_{\mathrm{Cr}}$ (serum creatinine), albumin, indications, loading dose, maintenance dose, dosing interval, infusion time and serum concentration were collected. Weight and $\mathrm{S}_{\mathrm{Cr}}$ were recorded on the day of blood sampling for serum concentration.

The dose and dosing interval were decided by attending physicians or clinical pharmacists, and the infusion time of vancomycin was 1 hour for dose lower than or equals to $500 \mathrm{mg}$, and 2 hours for dose between 500 to $1000 \mathrm{mg}$ and so on. The $\mathrm{C}_{\text {peak }} \mathrm{C}_{\text {trough }}$ were followed at 2 hours after the end of vancomycin infusion, and within 1 hour before vancomycin infusion. Both were followed after at least 5 doses of vancomycin. Vancomycin concentrations were analyzed by using first order pharmacokinetic principles (Sawchuk and Zaske method) to calculate $\mathrm{PK}$ parameters such as elimination rate constant $(\mathrm{K})$, halflife $\left(\mathrm{t}_{1 / 2}\right), \mathrm{V}_{\mathrm{d}}$, total body clearance $\left(\mathrm{CL}_{\text {vancomycin }}\right)$ and $\mathrm{AUC}_{24 \mathrm{~h}}[11]$. The formula was shown as follows:

$$
K(h r-1)=\ln (C p 2 / C p 1) / t,(C p 1 \text { and } C p 2)
$$

stands for two serum concentration in different time at steady state, $t=$ time difference between $C p 1$ and $C p 2$

$$
\begin{gathered}
t 1 / 2(h r)=0.693 / K \\
V d(L)=\left[\text { Dose }^{*}\left(1-\exp -k^{*} t \text { tin }\right) * \exp -k *(\tau-t i n)\right] /\left[\text { tin }^{*} \text { Ctrough } * k^{*}\left(1-\exp -k^{*} \tau\right)\right]
\end{gathered}
$$

( $\tau$ : dosing interval, $t_{\text {in }}$ : infusion time $\mathrm{C}_{\text {trough }}$ : serum trough concentration)

$$
\begin{gathered}
C L(L / h r)=V d^{*} K \\
A U C 24 h(m g * h r / L)=\text { Daily dose } / C L
\end{gathered}
$$

For each patient in the burn group, a control subject in intensive care unit was matched by creatinine clearance $\left(\mathrm{CL}_{\mathrm{Cr}}, \mathrm{mL} / \mathrm{min}\right)$. Matching was based on $\mathrm{CL}_{\mathrm{Cr}}$ value with a difference of $<30 \mathrm{~mL} /$ min between matched pair, or on different stages of chronic kidney disease with a range of $\mathrm{CL}_{\mathrm{Cr}}$ value between groups (>90,60-89, 30$59,<30 \mathrm{~mL} / \mathrm{min}$ ) [12]. The $\mathrm{CL}_{\mathrm{Cr}}$ was estimated by the Cockcroft and Gault (CG) method [13]. If patient's $\mathrm{S}_{\mathrm{Cr}}$ was lower than $1.0 \mathrm{mg} /$ $\mathrm{dL}$, it will be replaced by $1.0 \mathrm{mg} / \mathrm{dL}$ for better estimate of patient's renal function in intensive care unit [14]. For obese patients

[(true body weight-ideal body weight $) /$ ideal body weight $>30 \%)]$

the ideal body weight was used to estimate the $\mathrm{CL}_{\mathrm{Cr}}$.

The vancomycin serum concentrations were measured by a fluorescence polarisation immunoassay (AxSYM system, Abbott Laboratories, Abbott Park, Illinois, USA). The sensitivity of the assay (the lowest measurable level) was $2 \mathrm{mg} / \mathrm{L}$, and the coefficients of variation at 7.0, 35.0 and $75.0 \mathrm{mg} / \mathrm{L}$ were all less than $5 \%$.

For optimal vancomycin dose investigation, the population pharmacokinetics analysis was performed for burn patients by NONMEM version 7.2 (ICON Development Solutions, Ellicott City, MD, USA) with G77 FORTRAN compiler. Both one and twocompartment structural models were tested using the first-order conditional method of estimation (FOCE). Clearance and volume of distribution were estimated. A proportional error model was used to characterize the inter-individual variability (\% CV) of each parameter. Different residual error models (i.e., additive, proportional and combined additive and proportional) were examined in order to find the better error model to characterize the unexplained residual variability. Due to the limited sample size $(n=9)$, no attempts were made to identify the potential influential covariates.
The final model was assessed by visual inspection of the following diagnostic plots: (a) observed concentrations $v s$. individual predicted concentrations; (b) observed concentrations vs. predicted concentrations; (c) conditional weighted residuals (CWRES) vs. time and (d) absolute individual weighted residuals (IWRES) vs. individual predictions. A bootstrap resampling technique with 200 replications was conducted to evaluate the stability of the final model using Wings for NONMEM (WFN; Version 6.1, University of Auckland, New Zealand). The final model estimates were compared to the median and the $2.5^{\text {th }}$ and the $97.5^{\text {th }}$ percentiles of the parameter estimate obtained from successfully converged bootstrapping runs. The final population PK model was used for simulations to investigate the probability of target attainment (PTA) for different daily dose (2000 $\mathrm{mg}$ to $6000 \mathrm{mg}$ ). The pharmacodynamic target attainment was defined as achieving $\mathrm{AUC}_{24 \mathrm{~h}} / \mathrm{MIC} \geq 400$, and the MIC range values were $0.125,0.25,0.5$, 1.0 and $2.0 \mathrm{mg} / \mathrm{L}$ [8]. For each dose examined, 5,000 burn patients were simulated using Monte Carlo simulation in NONMEM and the percentage of patients exceeding an $\mathrm{AUC}_{24 \mathrm{~h}} / \mathrm{MIC}$ of 400 was computed.

Continuous data were summarized as mean with standard deviation. The demographic and PK data were compared by a twotailed paired $t$ test. Simple linear regression analysis was used to test the correlation between variables. A $p$-value of 0.05 or lower was considered statistically significant. The statistical analysis was performed using SPSS 11.5 (SPSS Inc, Chicago, Illinois, USA).

\section{Results}

Nine young adult burn patients were included in this study, and each individual was matched with a non-burn critical ill patient (control group). The mean surface area of second- and third-degree burn was $60 \%$ TBSA (total body surface area). There were no significant differences between the 2 groups in the demographic data except age and albumin (Table 1). Patients with burn injury were younger than the non-burn group (20.78 vs. 33.89 years-old) and had lower albumin level ( $2.6 \mathrm{vs} .3 .1 \mathrm{~g} / \mathrm{dL}$ ). All patients in the burn group received vancomycin for the treatment of MRSA empirically. Vancomycin was given before the $10^{\text {th }}$ day after burn except 1 started on $27^{\text {th }}$ day. The indications of vancomycin for the non-burn group were MRSA related bacteremia, pneumonia and wound infection in 3 patients respectively, and empirical use for the others.

In the burn group, the loading dose and daily maintenance dose was $25.42 \pm 4.53 \mathrm{mg} / \mathrm{kg}$ and $45.03 \pm 10.43 \mathrm{mg} / \mathrm{kg} /$ day respectively, which was significantly higher than that of non-burn group (14.46 \pm $1.40 \mathrm{mg} / \mathrm{kg}$ and $30.53 \pm 12.86 \mathrm{mg} / \mathrm{kg} /$ day) (Table 2). The vancomycin clearance was significantly higher in the burn group than that in the non-burn $(10.66 \mathrm{~L} / \mathrm{hr} \pm 3.28$ vs. $6.85 \mathrm{~L} / \mathrm{hr} \pm 3.54)$, corresponding to a $55 \%$ higher CL in burn patients $(p<0.05)$. Similarly, the trend of $\mathrm{K}$ and $\mathrm{V}_{\mathrm{d}}$, was higher in the burn group than the non-burn although it was statistically insignificant. $\mathrm{CL}_{\mathrm{Cr}}$ was not significantly correlated with vancomycin $C L$ in both groups $\left(\mathrm{r}=0.13, \mathrm{R}^{2}=0.02, P=0.74\right.$ in burn group vs. $\mathrm{r}=0.59, \mathrm{R}^{2=0.35}, P=0.09$ in non-burn group) (Figure 1 ). $\mathrm{C}_{\text {trough }}$ was not significantly correlated with $\mathrm{AUC}_{24 \mathrm{~b}}$ in the burn group ( $\mathrm{r}=0.63$, $\mathrm{R}^{2}=0.40, P=0.07$ ), but was correlated significantly in the non-burn group ( $\left.\mathrm{r}=0.98, \mathrm{R}^{2}=0.96, p<0.01\right)$ (Figure 2 ).

A one-compartment model with first-order elimination adequately characterized the observed concentration time profiles of vancomycin in burn patients. The final population pharmacokinetic model resulted in a clearance of $9.56 \mathrm{~L} / \mathrm{hr}$ with an inter-individual variability of $17.3 \%$. Volume of distribution is determined to be $50 \mathrm{~L}$ with an inter- 
Citation: Chien-Chih W, Li-Feng H, Jann-Tay W, Shu-Wen L, Eng-Kean Y (2018) The Pharmacokinetics, Optimal Dose and Therapeutic Monitoring of Vancomycin in Severe Burn Patients. J Mol Genet Med 12: 372 doi:10.4172/1747-0862.1000372

Page 3 of 7

\begin{tabular}{|c|c|c|c|c|c|c|c|c|c|c|}
\hline Patient No. ${ }^{a}$ & Age $(y r)$ & Sex $^{b}$ & $\mathrm{Ht}(\mathrm{cm})$ & Wt $(\mathbf{k g})$ & $\mathrm{S}_{\mathrm{cr}}(\mu \mathrm{mol} / \mathrm{L})$ & $\begin{array}{c}\mathrm{CL}_{\mathrm{cr}_{\mathrm{r}}}(\mathrm{mL} / \\
\min )\end{array}$ & $\begin{array}{c}\text { Albumin }(\mathbf{g} / \\
\mathrm{dL})\end{array}$ & \begin{tabular}{|c|} 
TBSA \\
burned $^{c}(\%)$
\end{tabular} & $\begin{array}{r}\text { Vancomycin initiatio } \\
\text { injury (d }\end{array}$ & $\begin{array}{l}\text { ion time after burn } \\
\text { (days) }\end{array}$ \\
\hline B1 & 18 & $\mathrm{~F}$ & 158 & 64.8 & 35.4 & 93.33 & 2.8 & 60 & 6 & i \\
\hline B2 & 21 & $\mathrm{~F}$ & 167 & 69 & 35.4 & 96.9 & 3.6 & 60 & 10 & 0 \\
\hline B3 & 23 & $\mathrm{~F}$ & 158 & 62.7 & 35.4 & 86.6 & 2.3 & 60 & 6 & 3 \\
\hline B4 & 21 & $\mathrm{~F}$ & 160 & 64.1 & 35.4 & 90.05 & 2.8 & 50 & 6 & \\
\hline B5 & 20 & $M$ & 175 & 78.5 & 53.0 & 130.8 & 2.8 & 50 & 6 & \\
\hline B6 & 24 & $\mathrm{~F}$ & 160 & $97^{\#}$ & 70.7 & 73.95 & 2.2 & 50 & 9 & 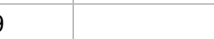 \\
\hline B7 & 20 & M & 160 & 68.8 & 53.0 & 114.7 & 2.2 & 50 & 6 & s \\
\hline B8 & 20 & M & 175 & 76.6 & 53.0 & 127.7 & 2.6 & 80 & 6 & s \\
\hline B9 & 20 & $M$ & 175 & 58 & 44.2 & 96.67 & 2.5 & 70 & 27 & 7 \\
\hline $\begin{array}{l}\text { Mean } \\
\text { (SD) }\end{array}$ & $\begin{array}{l}20.78^{*} \\
(1.79)\end{array}$ & & $\begin{array}{l}165.33 \\
(7.71)\end{array}$ & $\begin{array}{c}71.06 \\
(11.71)\end{array}$ & $\begin{array}{c}46.2 \\
(12.3)\end{array}$ & $\begin{array}{l}101.19 \\
(19.18)\end{array}$ & $\begin{array}{l}2.6^{*} \\
(0.4)\end{array}$ & $\begin{array}{l}60 \\
(11)\end{array}$ & $\begin{array}{l}9 \\
(7)\end{array}$ & ) \\
\hline C1 & 38 & $\mathrm{~F}$ & 160 & 63.6 & 53.0 & 76.58 & 3.4 & & & \\
\hline $\mathrm{C} 2$ & 18 & $M$ & 176 & 85.8 & 150.3 & 85.51 & 3.8 & & & \\
\hline C3 & 40 & $\mathrm{~F}$ & 160 & 60.5 & 26.5 & 71.42 & 2.8 & & & \\
\hline C4 & 38 & M & 170 & 53.9 & 53.0 & 76.36 & 2.8 & & & \\
\hline C5 & 18 & $M$ & 170 & 69.8 & 26.5 & 118.27 & 3.6 & & & \\
\hline C6 & 44 & $M$ & 173 & 52.6 & 61.9 & 70.13 & 2.2 & & & \\
\hline $\mathrm{C} 7$ & 42 & $M$ & 156 & 68 & 70.7 & 92.55 & 3.0 & & & \\
\hline C8 & 35 & $M$ & 171 & 68.3 & 61.9 & 99.6 & 3.3 & & & \\
\hline C9 & 32 & $M$ & 161 & $76.4^{\#}$ & 97.2 & 85.05 & 2.9 & & & \\
\hline $\begin{array}{l}\text { Mean } \\
\text { (SD) }\end{array}$ & $33.89(9.68)$ & & $\begin{array}{l}166.33 \\
(7.09)\end{array}$ & $\begin{array}{c}66.54 \\
(10.51)\end{array}$ & $66.8(38.1)$ & $\begin{array}{c}86.16 \\
(15.48)\end{array}$ & $3.1(0.5)$ & & & \\
\hline
\end{tabular}

Table 1: Demographic data in the burn and matched control groups.

\begin{tabular}{|c|c|c|c|c|c|c|c|c|c|c|c|c|}
\hline $\begin{array}{l}\text { Patient } \\
\text { No. }^{\mathrm{a}}\end{array}$ & $\begin{array}{c}\mathrm{LD}^{\mathrm{a}} \\
(\mathrm{mg} / \mathrm{kg})\end{array}$ & $\begin{array}{l}\mathrm{MD}^{\mathrm{b}} \\
(\mathrm{mg})\end{array}$ & $\begin{array}{l}\mathrm{DI}^{\mathrm{c}} \\
(\mathrm{hr})\end{array}$ & $\begin{array}{c}\text { Daily dose (mg/ } \\
\text { kg/day) }\end{array}$ & $\begin{array}{l}\text { Time of TDM } \\
\text { (days) }\end{array}$ & $\mathrm{C}_{\text {peak }}{ }^{e}(\mathrm{mg} / \mathrm{L})$ & $\begin{array}{l}C_{\text {trough }} \\
\text { (mg/L) }\end{array}$ & $\begin{array}{c}\mathrm{K} \\
(\mathbf{h r}-1)\end{array}$ & $\begin{array}{l}\mathbf{t}_{1 / 2} \\
(\mathbf{h r})\end{array}$ & $\begin{array}{l}\mathrm{CL} \\
(\mathrm{L} / \mathrm{hr})\end{array}$ & $\begin{array}{c}V_{d} \\
(L / k g)\end{array}$ & $\underset{\text { (mg*hr/L) }}{\text { AUC }_{24 h}}$ \\
\hline B1 & 23.15 & 1000 & 8 & 46.30 & 2 & 13.95 & 9.66 & 0.09 & 7.5 & 9.62 & 1.61 & 312 \\
\hline B2 & 28.99 & 1000 & 8 & 43.48 & 5 & 9.27 & 3.18 & 0.27 & 2.6 & 14.80 & 0.80 & 203 \\
\hline B3 & 23.92 & 1000 & 8 & 47.85 & 3 & 11.94 & 7.52 & 0.12 & 6.0 & 11.40 & 1.57 & 263 \\
\hline B4 & 31.2 & 1000 & 8 & 46.80 & 2 & 9.81 & 4.54 & 0.19 & 3.6 & 14.12 & 1.14 & 212 \\
\hline B5 & 25.48 & 1000 & 8 & 38.22 & 2 & 18.46 & 4.44 & 0.36 & 1.9 & 7.17 & 0.26 & 418 \\
\hline B6 & 30.93 & 1000 & 8 & 30.93 & 5 & 20.65 & 11.65 & 0.14 & 4.8 & 6.63 & 0.48 & 453 \\
\hline B7 & 21.8 & 1000 & 8 & 43.60 & 2 & 12.78 & 9.55 & 0.07 & 9.5 & 10.42 & 2.07 & 288 \\
\hline B8 & 26.11 & 1000 & 8 & 39.16 & 2 & 9.38 & 5.54 & 0.13 & 5.3 & 14.58 & 1.44 & 206 \\
\hline B9 & 17.24 & 1000 & 6 & 68.97 & 1 & 20.56 & 10.64 & 0.29 & 2.4 & 7.24 & 0.43 & 553 \\
\hline $\begin{array}{l}\text { Mean } \\
\text { (SD) }\end{array}$ & $\begin{array}{l}25.42^{*} \\
(4.53)\end{array}$ & -- & -- & $45.03^{*}(10.43)$ & -- & $14.09(4.66)$ & $7.41(3.09)$ & $0.18(0.10)$ & $4.8(2.5)$ & $\begin{array}{l}10.66^{*} \\
(3.28)\end{array}$ & $1.09(0.63)$ & $323(124)$ \\
\hline C1 & 15.00 & 500 & 6 & 31.44 & 2 & 8.31 & 3.66 & 0.27 & 2.6 & 10.21 & 0.59 & 196 \\
\hline $\mathrm{C} 2$ & 11.65 & 1000 & 24 & 11.65 & 3 & 19.04 & 4.98 & 0.07 & 10.3 & 3.60 & 0.63 & 278 \\
\hline C3 & 15.00 & 500 & 6 & 33.06 & 1 & 10.95 & 7.56 & 0.12 & 5.6 & 7.89 & 1.06 & 254 \\
\hline C4 & 16.69 & 1000 & 12 & 37.25 & 5 & 31.10 & 21.1 & 0.05 & 14.4 & 3.03 & 1.17 & 664 \\
\hline C5 & 14.32 & 500 & 6 & 28.65 & 5 & 7.77 & 3.13 & 0.30 & 2.3 & 10.84 & 0.52 & 184 \\
\hline C6 & 15.00 & 500 & 8 & 28.51 & 3 & 25.51 & 20.73 & 0.04 & 16.9 & 2.56 & 1.19 & 585 \\
\hline $\mathrm{C} 7$ & 14.7 & 750 & 12 & 22.05 & 3 & 10.60 & 3.99 & 0.12 & 5.7 & 7.80 & 0.94 & 192 \\
\hline C8 & 14.64 & 1000 & 6 & 58.56 & 6 & 14.00 & 9.85 & 0.18 & 3.9 & 11.44 & 0.95 & 350 \\
\hline C9 & 13.1 & 600 & 8 & 23.56 & 6 & 18.34 & 14.64 & 0.06 & 12.4 & 4.27 & 1.00 & 422 \\
\hline Mean (SD) & $14.46(1.40)$ & & & $30.53(12.86)$ & & $16.18(8.05)$ & $9.66(7.20)$ & $0.13(0.10)$ & $8.2(5.4)$ & $6.85(3.54)$ & $0.89(0.25)$ & 347 (176) \\
\hline
\end{tabular}

Table 2: Vancomycin data in the burn and matched control groups.

individual variability of $37.4 \%$ (Table 3 ). Residual variability was best described by an additive model and was determined to be $0.115 \mathrm{mg} / \mathrm{L}$.

The diagnostic plots of the final model are given in Figure 3. Overall, there was a good correlation between observed and individualand population-predicted vancomycin concentrations (Figures $3 \mathrm{~A}$ and 3B). No obvious bias pattern was observed for the plots of CWRES versus time (Figure 3C) and IWRES versus individual predicted concentrations (Figure 3D). From 200 bootstrap runs, 180 runs with successful minimization were included in the bootstrap analysis. All model estimates were similar between the bootstrap analysis and the final model. Overall the bootstrap analysis indicated that the final model was stable and estimated parameters were reasonably precise. 


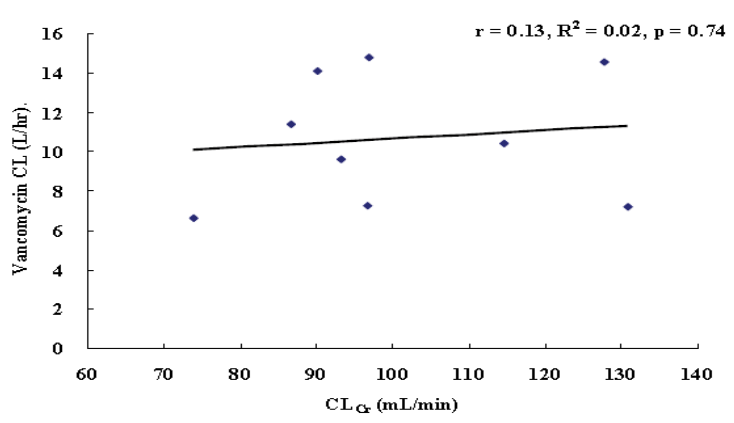

Figure 1A: Vancomycin clearance vs. creatinine clearance: Burn group.

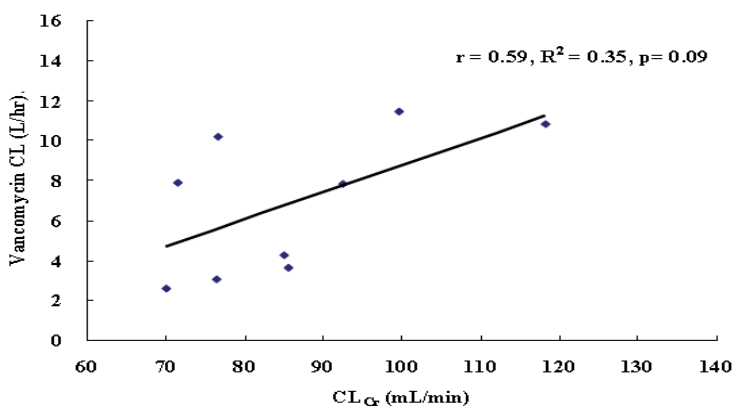

Figure 1B: Vancomycin clearance vs. creatinine clearance: Non-burn group.

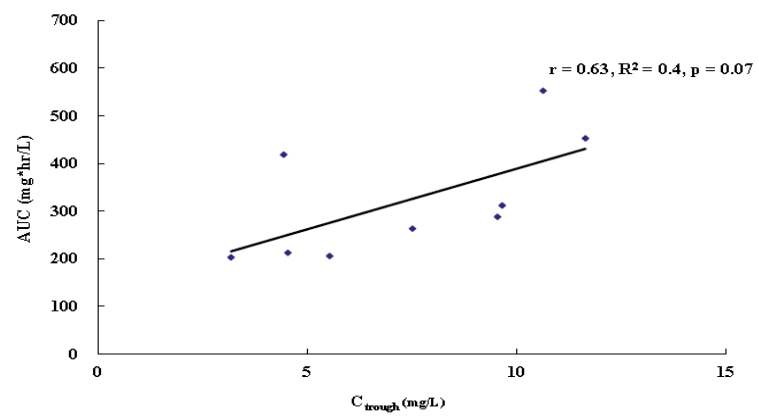

Figure 2A: Area under the curve vs. vancomycin trough concentration: Burn group.

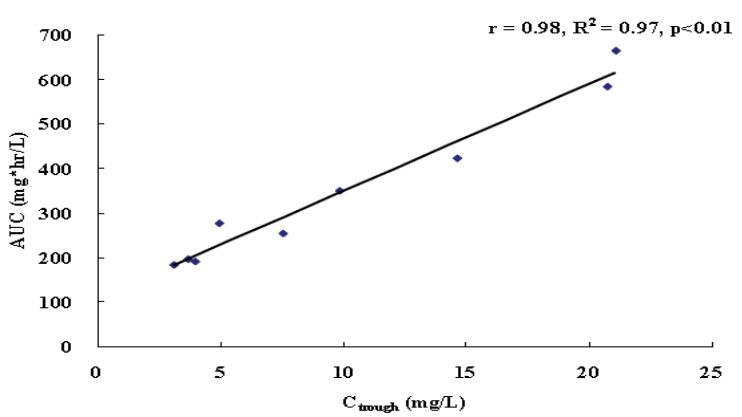

Figure 2B: Area under the curve vs. vancomycin trough concentration: Non-burn group.

\begin{tabular}{|c|c|c|}
\hline Parameters (unit) & Estimate (\%RSE) & $\begin{array}{c}200 \text { Bootstrap Replicates } \\
\text { Median }\left(2.5^{\text {th }}, 97.5^{\text {th }} \text { percentile }\right)\end{array}$ \\
\hline \multicolumn{3}{|c|}{ Fixed parameters } \\
\hline $\mathrm{CL}(\mathrm{L} / \mathrm{hr})$ & $9.56(9.4)$ & $9.41(7.87,11.3)$ \\
\hline$V_{d}(L)$ & $50.0(25.2)$ & $48.4(31.2,77.9)$ \\
\hline \multicolumn{3}{|c|}{ Interindividual variability } \\
\hline$\omega_{\mathrm{CL}}(\%)$ & $17.3(37.1)$ & $15.3(0.2,26.1)$ \\
\hline$\omega_{v}(\%)$ & $37.4(47.5)$ & $30.7(0.2,58.9)$ \\
\hline \multicolumn{3}{|c|}{ Residual variability } \\
\hline$\sigma(\mathrm{mg} / \mathrm{L})$ & $0.115(39.5)$ & $0.111(0.039,0.16)$ \\
\hline
\end{tabular}

$\omega$ : Inter-subject variability, $\sigma$ : Residual variability

Table 3: Pharmacokinetic parameters in burn group by population pharmacokinetic analysis.

The PTA $\left(\mathrm{AUC}_{24 \mathrm{~h}} / \mathrm{MIC}>400\right)$ for different daily dose of vancomycin by MIC was presented in Figure 4 . Based on the simulation results, it was observed that daily dose greater than 3000 and $5000 \mathrm{mg}$ yielded PTA $>90 \%$ against $\mathrm{MIC}$ of $\leq 0.5$ and $\leq 1.0 \mathrm{mg} / \mathrm{L}$, respectively. However, at a MIC of $2.0 \mathrm{mg} / \mathrm{L}$, even though increasing the daily dose up to $6000 \mathrm{mg}$ only provided a PTA of $10 \%$.

\section{Discussion}

MRSA infection or sepsis is a life-threatening clinical problem commonly encountered in severe burns. A potential nephrotoxic antibiotic, vancomycin, is usually the treatment of choice. The outcome is associated with proper antibiotic dosing. Inadequate doses will lead to suboptimal bactericidal activities leading to mortality or the development of resistance, while overdoses will cause nephrotoxicity. $\mathrm{C}_{\text {trough }}$ of $15-20 \mathrm{mg} / \mathrm{L}$ and $\mathrm{AUC}_{24 \mathrm{~h}} / \mathrm{MIC}>400$ have been recommended.

As in other studies in the literature, this study has shown that the clearance of vancomycin is augmented in severe burn injury [4-6]. The results provide an explanation for the observation that although burn patients received higher loading and maintenance dose of vancomycin, the $\mathrm{C}_{\text {trough }}$ was not significantly higher than that in the non-burn group. Increased glomerular filtration rate, extensive loss through burn wounds, and decreased or altered serum binding proteins are possible explanations for the enhanced vancomycin elimination noted in the burn patients [2]. A study of serum protein-binding characteristic of vancomycin has shown that vancomycin preferentially binds to albumin and immunoglobulin A (IgA), the serum level of which was found to decrease 2 days after burns $(<0.001)$ [15]. Consequently, it leads to increased elimination due to less protein binding. Our data was compatible with this finding by lower albumin level and higher vancomycin clearance in burn group.

Besides higher clearance in the burn group, the $V_{d}$ is also higher in the burn group. This could be attributed to more aggressive resuscitation in the burn group than that in the non-burn group. According to Parkland formula, the total amount of resuscitation fluids for burn group was around 14.4 liter (TBSA $(\%) \times$ body weight $\times 4 \mathrm{~mL}$ ), while only around 2 liter $(30 \mathrm{~mL} / \mathrm{kg})$ was given for non-burn group based on the recommendation of fluid resuscitation in sepsis patients $[16,17]$. This also further explains why the $\mathrm{C}_{\text {trough }}$ was not significantly higher in the burn group than that in the non-burn group although larger dose was administered to burn group.

Our results have shown that $\mathrm{C}_{\text {trough }}$ was not correlated well to $\mathrm{AUC}_{24 \mathrm{~h}}$ in burns patients than that in control patients. The result is compatible to the statements by Michael N. Neely who said that the traditional approach to therapeutic drug monitoring (TDM) by comparing the 
(A)

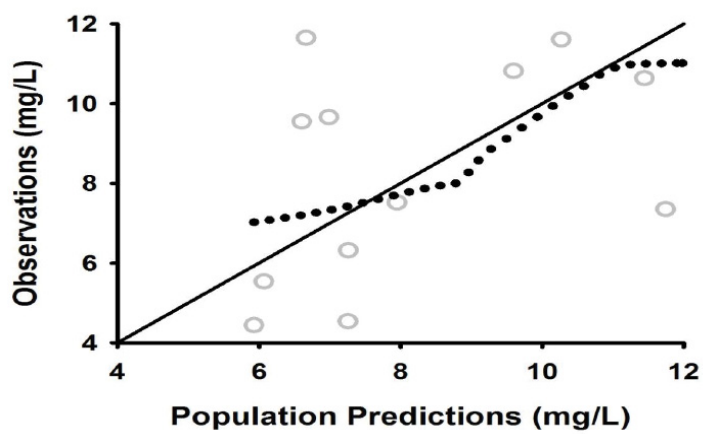

(C)

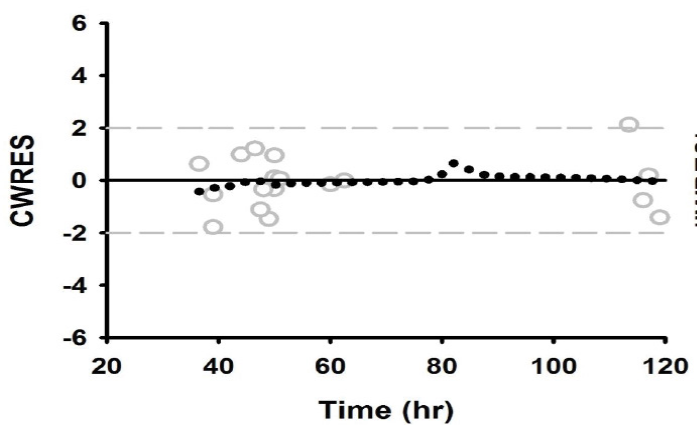

(B)

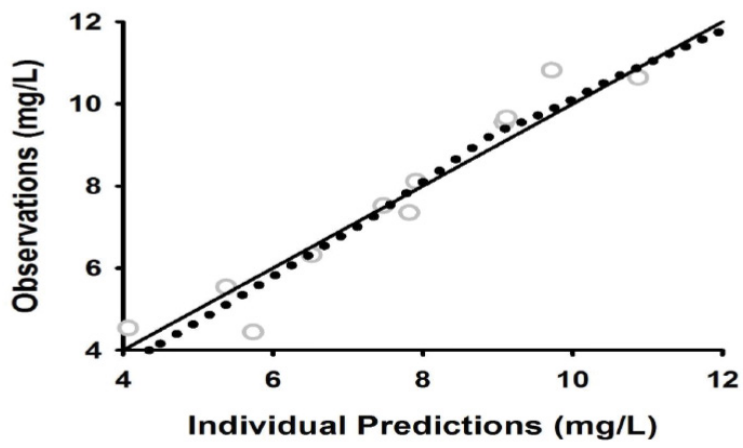

(D)

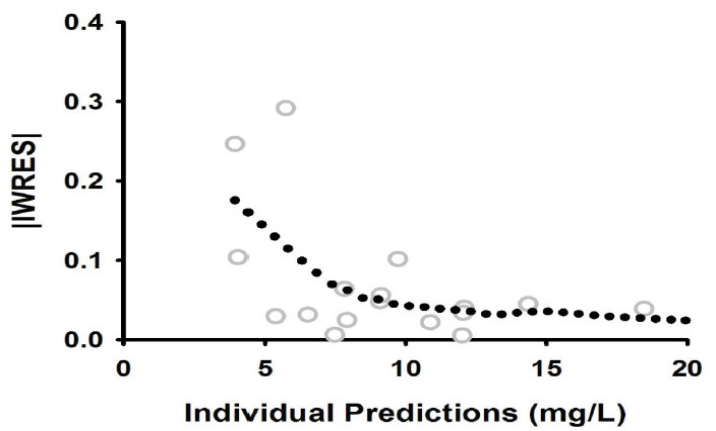

Note: Solid and dotted line: the line of identity and LOESS smoothed fit, respectively.

Figure 3: Basic goodness-of-fit plots for the final population pharmacokinetic model

(A) Observations vs. population predictions

(B) Observations vs. individual predictions.

(C) Conditional weighted residuals (CWRES) vs. time

(D) Absolute individual weighted residuals (IWRES) vs. individual predictions.

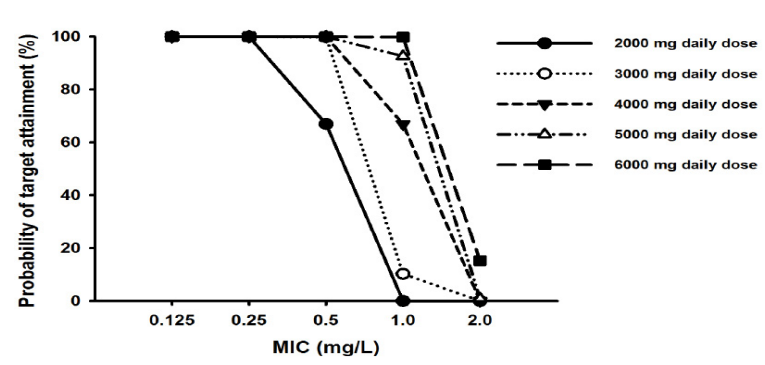

Figure 4: Probability of target attainment of $\mathrm{AUC}_{24 \mathrm{~h}} / \mathrm{MIC}>400$ for 5000 simulated burn subjects following different daily doses of vancomycin.

$\mathrm{C}_{\text {trough }}$ to a predefined range is a very poor surrogate for estimation of the AUC and overall vancomycin exposure [9]. He emphasized that $\mathrm{C}_{\text {trough }}$ will underestimate the true $\mathrm{AUC}_{24 \mathrm{~h}}$ by about $25 \%$. However, on the other hand, our study also has shown that $\mathrm{C}_{\text {trough }}$ was significantly correlated with $\mathrm{AUC}_{24 \mathrm{~h}}$ in the non-burn patient group. These findings are compatible to IDSA guidelines, which stated that $\mathrm{C}_{\text {trough }}$ is a tool to monitor the therapeutic level and toxicity of vancomycin due to its good correlation to $\mathrm{AUC}_{24 \mathrm{~h}}$ in the general population [1]. In fact, the association between $\mathrm{C}_{\text {trough }}$ and $\mathrm{AUC}_{24 \mathrm{~h}}$ may be explained by the pathophysiological changes in burns. Following the ebb phase of early severe burn injury, more aggressive fluid resuscitation than that in control group results in higher than normal cardiac output and greater blood perfusion to the liver and kidneys, consequently increases vancomycin clearance and $\mathrm{V}_{\mathrm{d}}[2]$. Besides, there is tremendous interpatient or intrapatient variability, especially in burns of different stages. These factors may explain why $\mathrm{C}_{\text {trough }}$ may not be an appropriate reference to assess the optimal therapeutic vancomycin level in burns.

Some studies showed that the correlation between $\mathrm{C}_{\text {trough }}$ and the actual $\mathrm{AUC}_{24 \mathrm{~h}}$ were subjected to individual variations such as dosing interval and infusion time $[9,10]$. Again, these findings were against the approach to use $\mathrm{C}_{\text {trough }}$ alone as a reference. $\mathrm{C}_{\text {trough }}$ would be proportional to $\mathrm{AUC}_{24 \mathrm{~h}}$ only under the situation of fixing dosing interval and infusion time. In burn patients, higher dose of vancomycin is needed and this makes fixing infusion time difficult due to the concern of red man syndrome [18]. This further ensures the necessity of estimate of $\mathrm{AUC}_{24 \mathrm{~h}}$ by at least 2 points of serum concentration, instead of $\mathrm{C}_{\text {trough }}$ alone.

As $\mathrm{C}_{\text {trough }}$ does not correlate to $\mathrm{AUC}_{24 \mathrm{~h}}$ well in severe burns patients, two points of serum concentration were suggested in our study for the mathematical derivation of $\mathrm{PK}$ parameters and $\mathrm{AUC}_{24 \mathrm{~h}}$, which are beneficial in vancomycin serum level monitoring and dose adjustment in severe burns [19]. Because of increasing CL and $V_{d}$ in severe burn patients, the optimal dose of vancomycin in this population would be 
higher than that in general population. If vancomycin MIC of MRSA was $1 \mathrm{mg} / \mathrm{L}, 5000 \mathrm{mg}$ of vancomycin daily was needed to have the better chance to achieve the target of $\mathrm{AUC}_{24 \mathrm{~h}} / \mathrm{MIC}>400$ in this study. Because of vancomycin MIC creep in MRSA and a high percentage of vancomycin MIC being $1 \mathrm{mg} / \mathrm{L}$, the initial vancomycin dosing of 5000 $\mathrm{mg}$ should be given in severe burn patients with normal renal function $\left(\mathrm{CL}_{\mathrm{Cr}} 90 \mathrm{~mL} / \mathrm{min}\right)$ before confirming MIC data [20]. However, due to wide individual variations among burn patients, closed serum level monitoring is still highly recommended. As the half-life of vancomycin $(4.8 \pm 2.5$ hours $)$ is comparatively short in burn patients, serum concentration can be checked 1 to 2 days after initiation of vancomycin to ensure efficacy and safety.

Our results have confirmed that large burn size and initiation of vancomycin infusion within 2 weeks of burn in our study population have yielded a high value of $C L$ and $V_{\mathrm{d}}$. The results are compatible to the statement that burn size and timing of vancomycin infusion affect PK $[5,21]$. As vancomycin is mainly excreted by kidneys, previous study has shown that estimated $\mathrm{CL}_{\mathrm{Cr}}$ is a good predictor of vancomycin clearance [22]. However, this is not true in our study, as forming an initial dose nomogram based on $\mathrm{CL}_{\mathrm{Cr}}$ is not possible (Figure 1).

These findings are compatible to other study results stating that creatinine-based formula is a less reliable tool for therapeutic drug monitoring in severe burn patients. The complicated burn pathophysiology has shown that cystatin C-based formula, Cockcroft and Gault methods, Modification of Diet in Renal Disease (MDRD) equations and Chronic Kidney Disease Epidemiology Collaboration (CKD-EPI) equation are imprecise and inaccurate for renal function monitoring $[23,24]$. Besides dehydration due to the tremendous loss of fluid, the suppressed renal function by toxic substances or the decreased renal flow, the decreased serum creatinine production due to the loss of muscle mass, the increased glomerular filtration rate due to the increased cardiac output during the hypermetabolic state, and the disturbed liver metabolism have significantly affect the reliability of $\mathrm{CL}_{\mathrm{Cr}}$ measurement as a tool for antibiotic dosing. In fact, the glomerular filtration rate is overestimated by creatinine clearance in renal failure due to tubular creatinine secretion [25]. In short, the use of creatinine-based formula which is only suitable to patients with stable renal function is inappropriate in severe burn patients. However, urine collection for creatinine clearance remains the clinically gold standard for antibiotic dosing in these patients.

The main drawback of the study is quite small sample size, besides the inherent limitations of retrospective studies. The differences of vancomycin $V_{d}$ between groups may be significant if the sample size is large, and multi-centre prospective study is thus indicated. Also, further studies are needed to confirm the dose recommended in this study.

\section{Conclusion}

Our results have proved that $\mathrm{C}_{\text {trough }}$ alone was not an appropriate reference for monitoring the therapeutic and toxic effect of vancomycin in severe burn patients due to its poor correlation with $\mathrm{AUC}_{24 \mathrm{~h}}$, in which two points of serum concentration are required. Creatinine clearancebased dosage formula is not feasible due to its lack of correlation with vancomycin clearance in burn patients. We suggest a daily dose of at least $5000 \mathrm{mg}$ to attain an optimal therapeutic value of $\mathrm{AUC}_{24 \mathrm{~h}} / \mathrm{MIC} \square$ 400 if vancomycin MIC was $1 \mathrm{mg} / \mathrm{L}$ of MRSA in severe burn patients with normal renal function.

\section{Conflict of Interest}

There was no conflict of interest in this study.

\section{Funding}

This research did not receive any specific grant from funding agencies in the public, commercial, or not-for- profit sectors.

\section{References}

1. Rybak M, Lomaestro B, Rotschafer JC (2009) Therapeutic monitoring of vancomycin in adult patients: A consensus review of the American Society of Health-System Pharmacists, the Infectious Diseases Society of America, and the Society of Infectious Diseases Pharmacists. Am J Health Syst Pharm 66: 82-98.

2. Blanchet B, Jullien V, Vinsonneau C, Tod M (2008) Influence of burns on pharmacokinetics and pharmacodynamics of drugs used in the care of burn patients. Clin Pharmacokinet 47: 635-654.

3. Udy AA, Roberts JA, Boots RJ, Paterson DL, Lipman J (2010) Augmented renal clearance: Implications for antibacterial dosing in the critically ill. Clin Pharmacokinet 49: 1-16.

4. Dolton M, Xu H, Cheong E (2010) Vancomycin pharmacokinetics in patients with severe burn injuries. Burns 36: 469-476.

5. Elligsen M, Walker SA, Walker SE, Simor A (2011) Optimizing initial vancomycin dosing in burn patients. Burns 37: 406-414.

6. Akers KS, Cota JM, Chung KK, Renz EM, Mende K, et al. (2012) Serum vancomycin levels resulting from continuous or intermittent infusion in critically ill burn patients with or without continuous renal replacement therapy. J Burn Care Res 33: e254-262.

7. Carter BL, Damer KM, Walroth TA, Buening NR, Foster DR, et al. (2015) A systematic review of vancomycin dosing and monitoring in burn patients. $J$ Burn Care Res 36: 641-650.

8. Moise-Broder PA, Forrest A, Birmingham MC, Schentag JJ (2004) Pharmacodynamics of vancomycin and other antimicrobials in patients with Staphylococcus aureus lower respiratory tract infections. Clin Pharmacokinet 43: $925-942$.

9. Neely MN, Youn G, Jones B (2014) Are vancomycin trough concentrations adequate for optimal dosing? Antimicrob Agents Chemother 58: 309-316.

10. Patel N, Pai MP, Rodvold KA, Lomaestro B, Drusano GL, et al. (2011) Vancomycin: We can't get there from here. Clin Infec Dis 52: 969-974.

11. Sawchuk RJ, Zaske DE, Cipolle RJ, Wargin WA, Strate RG (1977) Kinetic model for gentamicin dosing with the use of individual patient parameters. Clin Pharmacol Ther 21: 362-369

12. Johnson CA, Levey AS, Coresh J, Levin A, Lau J, et al. (2004) Clinical practice guidelines for chronic kidney disease in adults: Part I. Definition, disease stages, evaluation, treatment, and risk factors. Am Fam Physician 70: 869-876.

13. Cockcroft DW, Gault MH (1976) Prediction of creatinine clearance from serum creatinine. Nephron 16: 31-41.

14. Robert S, Zarowitz BJ, Peterson EL, Dumler F (1993) Predictability of creatinine clearance estimates in critically ill patients. Crit Care Med 21: 1487-1495.

15. Sun H, Maderazo EG, Krusell AR (1993) Serum protein-binding characteristics of vancomycin. Antimicrob Agents Chemother 37: 1132-1136.

16. Baxter CR (1974) Fluid volume and electrolyte changes of the early postburn period. Clin Plast Surg 1: 693-703.

17. Rhodes A, Evans LE, Alhazzani W (2017) Surviving sepsis campaign: International Guidelines for Management of Sepsis and Septic Shock: 2016. Intens Care Med 43: 304-377.

18. Wilhelm MP, Estes L (1999) Symposium on antimicrobial agents-Part XII. Vancomycin. Mayo Clinic proceedings 74: 928-935.

19. Pai MP, Neely M, Rodvold KA, Lodise TP (2014) Innovative approaches to optimizing the delivery of vancomycin in individual patients. Adv Drug Deliv Rev 77: 50-57.

20. Steinkraus G, White R, Friedrich L (2007) Vancomycin MIC creep in nonvancomycin-intermediate Staphylococcus aureus (VISA), vancomycinsusceptible clinical methicillin-resistant $S$. aureus (MRSA) blood isolates from 2001-2005. J Antimicrobial Chemother 60: 788-794.

21. Conil JM, Georges B, Breden A (2006) Increased amikacin dosage requirements in burn patients receiving a once-daily regimen. Int $\mathrm{J}$ Antimicrob Agents 28: 226-230. 
Citation: Chien-Chih W, Li-Feng H, Jann-Tay W, Shu-Wen L, Eng-Kean Y (2018) The Pharmacokinetics, Optimal Dose and Therapeutic Monitoring of Vancomycin in Severe Burn Patients. J Mol Genet Med 12: 372 doi:10.4172/1747-0862.1000372

22. Rodvold KA, Blum RA, Fischer JH (1988) Vancomycin pharmacokinetics in patients with various degrees of renal function. Antimicro Agent chemother 32 : 848-852.

23. Conil JM, Georges B, Fourcade O (2007) Assessment of renal function in clinical practice at the bedside of burn patients. Br J Clin Pharmacol 63: 583-594.
24. Carlier M, Dumoulin A, Janssen A (2015) Comparison of different equations to assess glomerular filtration in critically ill patients. Intens Care Med 41: 427-435.

25. Bauer JH, Brooks CS, Burch RN (1982) Clinical appraisal of creatinine clearance as a measurement of glomerular filtration rate. Am J Kidney Dis 2 : 337-346. 